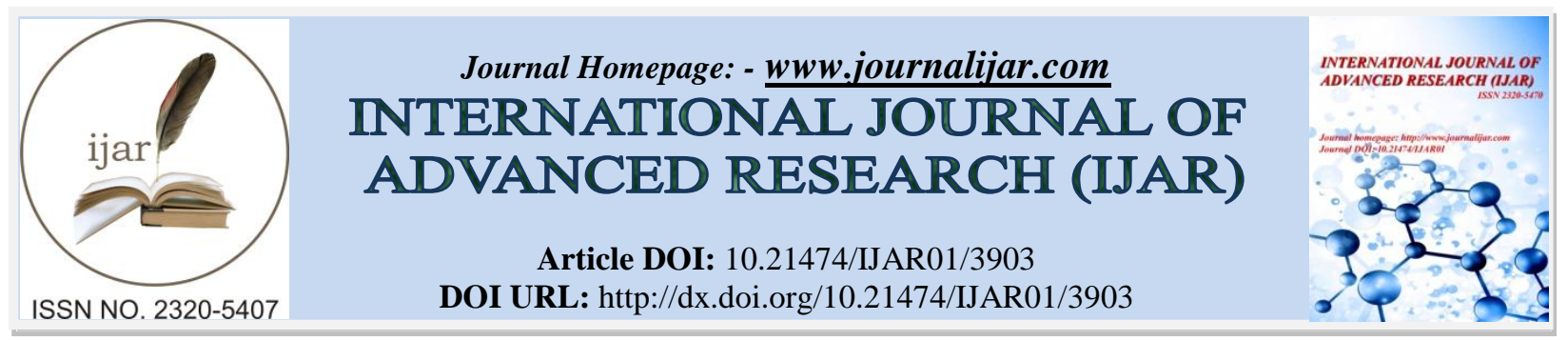

RESEARCH ARTICLE

\title{
GC-MS ANALYSIS AND ANTIMICROBIAL ACTIVITY OF SUDANESE PENNISETUM GLAUCUM FIXED OIL.
}

\author{
${ }^{*}$ Abdel Karim M. ${ }^{1}$, Asma. M. H. ${ }^{2}$ and Inas.O. ${ }^{3}$. \\ 1. Sudan University of Science and Technology, Faculty of Science. \\ 2. University of Nyala, Faculty of Education. \\ 3. University of Bahri, Faculty of Applied and Industrial Chemistry.
}

\section{Manuscript Info}

\section{Manuscript History}

Received: 01 February 2017

Final Accepted: 01 March 2017

Published: April 2017

Key words:-

Pennisetum glaucum , GC-MS analysis,

Fixed oil, Antimicrobial Activity.

\begin{abstract}
Millets which were cultivated thousands of years ago are one of the most important cereal crops. This study was carried out to investigate the constituents of Pennisetum glaucum fixed oil . GC-MS analysis revealed the presence of 15 components dominated by: 9,12octadecadienoic acid methyl ester $(49.66 \%)$; 9-octadecenoic acid methyl ester(33.16\%) ; hexadecanoic acid methyl ester (6.87\%) ; methyl stereate $(4.28 \%)$.The disc diffusion bioassay was used to assess the antimicrobial activity of the oil. Pennisetum glaucum oil showed activity against all test organisms. It showed excellent activity against Bacillus subtilis and other bacteria except Staphylococcus aureus where a moderate activity was observed . It also showed good activity against the fungal species Candida albicans and moderate against Aspergillus niger.
\end{abstract}

Copy Right, IJAR, 2017,. All rights reserved.

\section{Introduction:-}

Millets represent a collective term referring to a number of small-seeded annual grasses reaching $0.5-4 \mathrm{~m}$ in height.Millet is a cereal crop plant belonging to the grass family, Gramineae (FAO, 1972). Most of millet genera are widely distributed throughout the tropics and subtropics of the world (De Wet, 2006).

Millets which were cultivated thousands of years ago are one of the most important cereal crops(Lu et.al.,2005).In Africa it extends as belt from Sudan to Senegal.The plant can survive in arid regions with soils of low fertility (Girish et.al.,2015).In western Africa considerable morphological diversity of millet is observed. India is considered as a secondary center of diversity (Shweta, 2015).

The plant has several health promoting abilities .Millets provide minerals, significant amount of essential amino acids, fatty acids, vitamins, proteins and dietary fiber(Obilane and Manyasa, 2002; Devi et.al.,2011) . Regular consumption of whole grain, like millets, has been shown to reduce risk of diabetes, gastrointestinal disorders and cardiovascular diseases as demonstrated by some epidemiological studies(Shweta,2015)). Millets have low glycemic index and their fiber, magnesium, phenolics and tannins content reduce the risk of diabetes since they slow the sudden increase in blood glucose and insulin levels(Montonen et.al.,2003). Due to its high content of the micronutrients iron and zinc, millet, is considered useful in case of anaemia(Shweta,2015 ; Hoseney et.al. , 1987).Millets also have the potential to attenuate many degenerative diseases like hypertension. This is attributed to their antioxidant properties. Since millets do not contain gluten, they are usefull in celiac disease (Amadou 
et.al.,2011; Taylor and Emmambux,2008).Millets possess anticancer properties and this is due to their phenolic and tannin content(Grimmer et.al.,1992).

Pennisetum glaucum (Pearl millet) has about 400 genera. It is the major millet grown in Africa and it is the fourth most important cereal food crop grown in India (FAO, 1972).Pearl millet possesses high phenolic content and high free radical scavenging activity and therefore can serve as a source of antioxidants in diets (Odusola et.al.,2013).

\section{Materials and Methods:-}

Materials:-

\section{Plant material:-}

Seeds of Pennisetum glaucum were purchased from the local market-Omdurman, Sudan. The plant was identified and authenticated by the Department of Phytochemistry and Taxonomy, National Research Center, KhartoumSudan.

\section{Test organisms:-}

Microorganisms used for antimicrobial assay are shown in Table 1.

Table 1:- Test organisms

\begin{tabular}{|l|l|l|}
\hline Ser. No & Micro organism & Type \\
\hline 1 & Bacillus subtilis & G+ve \\
\hline 2 & Staphylococcus aureus & G+ve \\
\hline 3 & Pseudomonas aeroginosa & G-ve \\
\hline 4 & Escherichia coli & G-ve \\
\hline 5 & Aspergillus niger & fungus \\
\hline 6 & Candida albicans \\
\hline
\end{tabular}

\section{Methods:-}

Extraction of oil from Pennisetum glaucum seeds:-

Powdered seeds of Pennisetum glaucum $(400 \mathrm{~g})$ were extracted with n-hexane by maceration .The solvent was removed in vacuo to give the fixed oil.

Oil sample was esterified at room temperature via a methanolic solution of sodium hydroxide ( $2 \mathrm{~g}$ of sodium hydroxide in $100 \mathrm{ml}$ methanol) and methanolic sulphuric acid (1 $\mathrm{ml}$ of concentrated sulphuric acid in $99 \mathrm{ml}$ methanol). Following esterification, the oil was studied by gas chromatography - mass spectrometry using a Shimadzo instrument equipped with a RTX-5MS column (30m,length ; $0.25 \mathrm{~mm}$ diameter ; $0.25 \mu \mathrm{m}$, thickness). Carrier gas was analytical grade Helium (purity $99.99 \%$ ) . Oven temperature program is shown below:

Rate: - ; Temperature $: 150^{0} ; \quad$ Hold Time $\left(\min ^{-1}\right): 1.00$

Rate : $4.00 ;$ Temperature $: 300^{0} ; \quad$ Hold Time $\left(\mathrm{min}^{-1}\right): 0.00$

Other chromatographic conditions are tabulated below:

Table 2:- Chromatographic conditions.

\begin{tabular}{|l|l|}
\hline Column oven temperature & $150.0^{\circ} \mathrm{C}$ \\
Injection temperature & $300.0^{\circ} \mathrm{C}$ \\
Injection mode & Split \\
Flow control mode & Linear velocity \\
Pressure & $139.3 \mathrm{KPa}$ \\
Total flow & $50.0 \mathrm{ml} / \mathrm{min}$ \\
Column flow & $1.54 \mathrm{ml} / \mathrm{sec}$ \\
Linear velocity & $47.2 \mathrm{~cm} / \mathrm{sec}$. \\
Purge flow & $3.0 \mathrm{ml} / \mathrm{min}$ \\
Spilt ratio & -1.0 \\
\hline
\end{tabular}




\section{Antimirobial sensitivity test:-}

Powdered agar (approximately 38g) was dispersed in 1 liter of distilled water for ten minutes. Then it was heated in a water bath to dissolve, swirled to mix and sterilized (autoclave) at $121^{\circ} \mathrm{C}$ for 15 minutes .It was then cooled at $47^{\circ}$, mixed well and poured into sterile Petri dishes.

Aliquots $(20 \mathrm{ml})$ of molten agar were distributed into sterile Petri dishes. About $(0.1 \mathrm{ml})$ of the standardized bacterial stock suspension $\left(10^{8}-10^{9}\right.$ colony-forming units $\left./ \mathrm{ml}\right)$ were soaked on agar medium plates using sterile cotton . Sterilized filter paper discs (6mm diameter) were soaked in test sample solution and then placed on the surface of the test bacteria plates. The plates were then incubated for $24 \mathrm{~h}$. Following incubation the, diameter of inhibition zones were measured in triplicates and averaged. The same procedure was adopted for the standard antimicrobial chemotherapeutics (positive control). DMSO was used as negative control.

For antifungal activity, potato dextrose agar was used instead of nutrient agar. Incubation period was continued for $72 \mathrm{~h}$.

\section{Results and discussion:-}

The total ion chromatogram is shown in Fig. 1, while oil constituents are shown in Table 3.

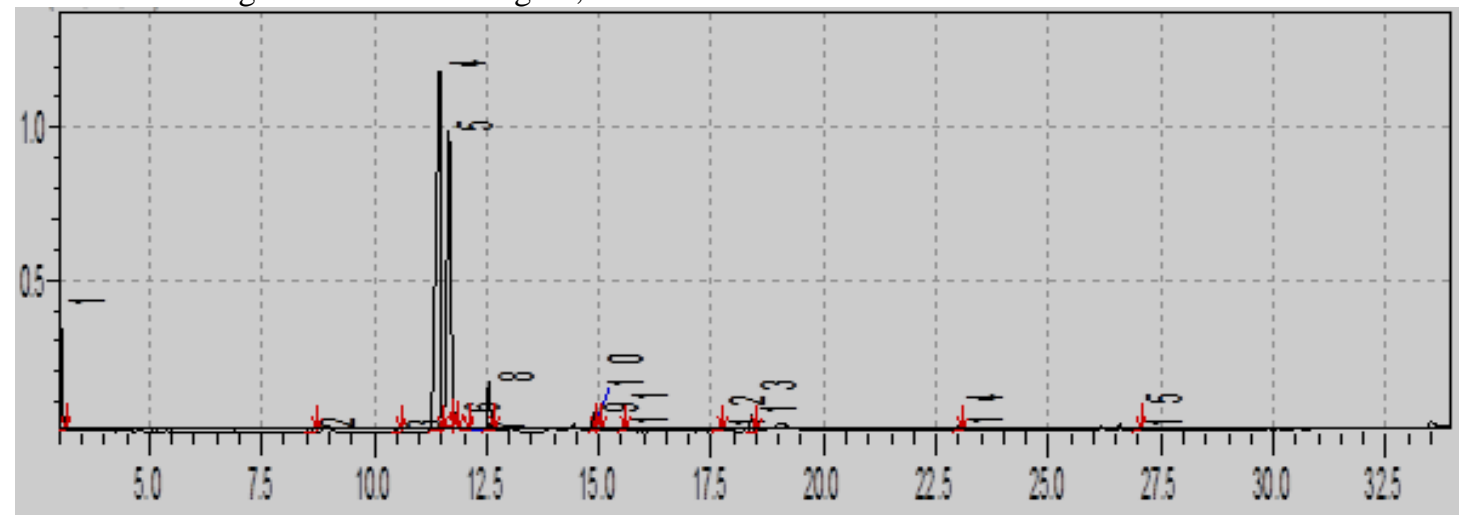

Fig.1:- Total ion Cheromatograms

Table 3:- Constituents of Pennisetum glaucum oil

\begin{tabular}{r|r|r|r|l|}
\hline Peak\# & R.Time & Area & Area \% & Name \\
\hline 1 & 3.005 & 12253689 & 6.87 & Hexadecanoic acid,methyl ester \\
\hline 2 & 8.566 & 619208 & 0.35 & 10,13 -Octadecadienoic acid, methyl ester \\
\hline 3 & 10.484 & 175028 & 0.10 & Heptadecanoic acid, 16-methyl-, methyl ester \\
\hline 4 & 11.457 & 88599963 & 49.66 & 9,12 -Octadecadienoic acid (Z,Z)-, methyl ester \\
\hline 5 & 11.661 & 59158683 & 33.16 & 9-Octadecenoic acid (Z)-, methyl ester \\
\hline 6 & 11.815 & 2042783 & 1.15 & ll-Octadecenoic acid, methyl ester \\
\hline 7 & 11.970 & 317036 & 0.18 & cis-13-Octadecenoic acid, methyl ester \\
\hline 8 & 12.548 & 7632582 & 4.28 & Methyl stearate \\
\hline 9 & 14.873 & 1784816 & 1.00 & Linoleic acid ethyl ester \\
\hline 10 & 14.989 & 1480288 & 0.83 & 8-Octadecenoic acid, methyl ester \\
\hline 11 & 15.520 & 624751 & 0.35 & Nonadecanoic acid, methyl ester \\
\hline 12 & 17.680 & 487031 & 0.27 & cis-ll-Eicosenoic acid, methyl ester \\
\hline 13 & 18.395 & 2159375 & 1.21 & Methyl 18-methylnonadecanoate \\
\hline 14 & 22.988 & 620021 & 0.35 & Docosanoic acid, methyl ester \\
\hline 15 & 26.959 & 443431 & 0.25 & Tetracosanoic acid, methyl ester \\
\hline & & 178398685 & 100.00 & \\
\hline
\end{tabular}

Major constituents of oil are discussed below:

i) 9,12-Octadecadienoic acid methyl ester $(\mathbf{4 9 . 6 6 \% )}$ :-

The mass spectrum of 9,12-octadecadienoic acid methyl ester is shown in Fig 2 . The peak at m/z 294( RT 11.457) corresponds $\mathrm{M}^{+}\left(\mathrm{C}_{19} \mathrm{H}_{34} \mathrm{O}_{2}\right)^{+}$. The peak at $\mathrm{m} / \mathrm{z} 263$ correspond to loss of a methoxyl . 


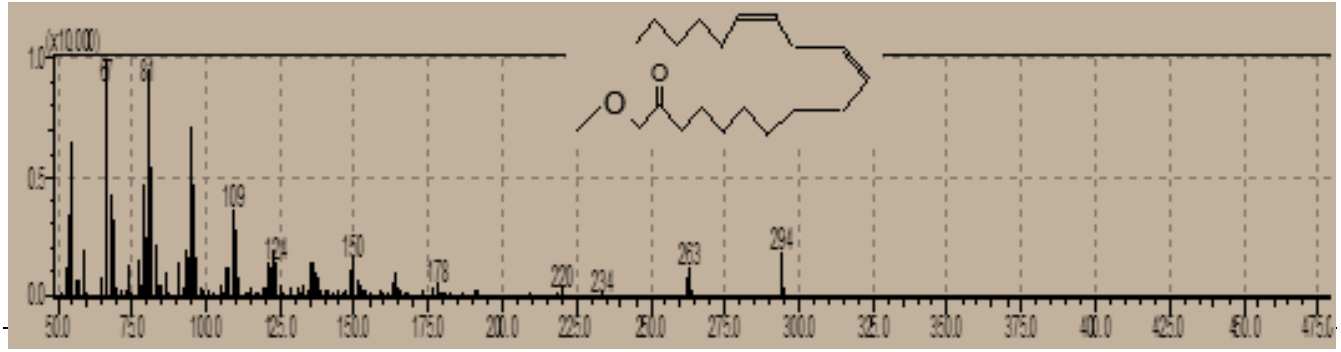

Fig.2:- Mass spectrum of 9,12-octadecadienoic acid methyl ester

ii) 9-Octadecenoic acid methyl ester(33.16\%):-

The EI mass spectrum of 9-octadecenoic acid methyl ester is shown in Fig.3. The signal at m/z 296(RT 11.661) corresponds $\mathrm{M}^{+}\left(\mathrm{C}_{19} \mathrm{H}_{36} \mathrm{O}_{2}\right)^{+}$.The peak at $\mathrm{m} / \mathrm{z} 264$ is due to loss of methoxyl function.

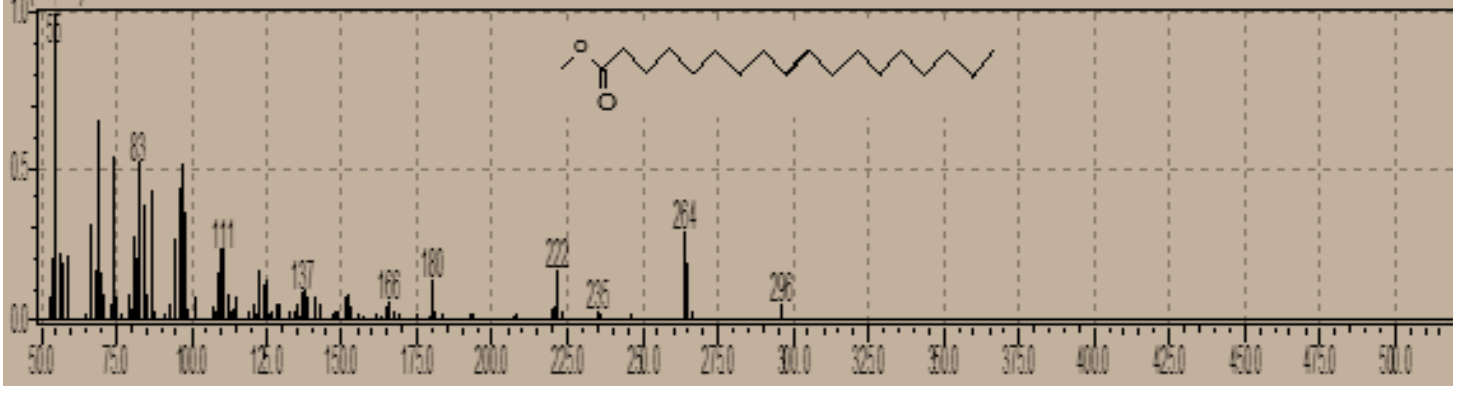

Fig. 3:- Mass spectrum of 9-octadecenoic acid methyl ester

iii)Hexadecanoic acid methyl ester $(6.87 \%)$ :-

The molecular ion $\mathrm{M}^{+}\left(\mathrm{C}_{17} \mathrm{H}_{34} \mathrm{O}_{2}\right)^{+}$for hexadecanoic acid appeared at $\mathrm{m} / \mathrm{z} 270(\mathrm{RT}, 3.005)$. The peak at $\mathrm{m} / \mathrm{z} 239$ is due to loss of a methoxyl (Fig.4).

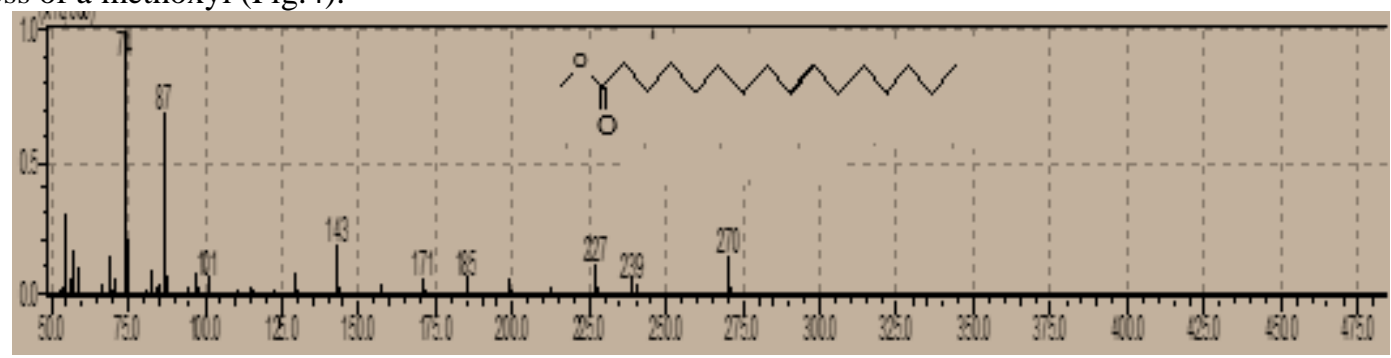

Fig.4:- mass spectrum of hexadecanoic acid methyl ester

iv) Methyl stearate(4.28\%)

The mass spectrum of methyl stearate is displayed in Fig.5 . The peak at m/z298(RT 12.548) corresponds $\mathrm{M}^{+}$ $\left(\mathrm{C}_{19} \mathrm{H}_{38} \mathrm{O}_{2}\right)^{+}$, while the signal at $\mathrm{m} / \mathrm{z} 267$ accounts for loss of a methoxyl.

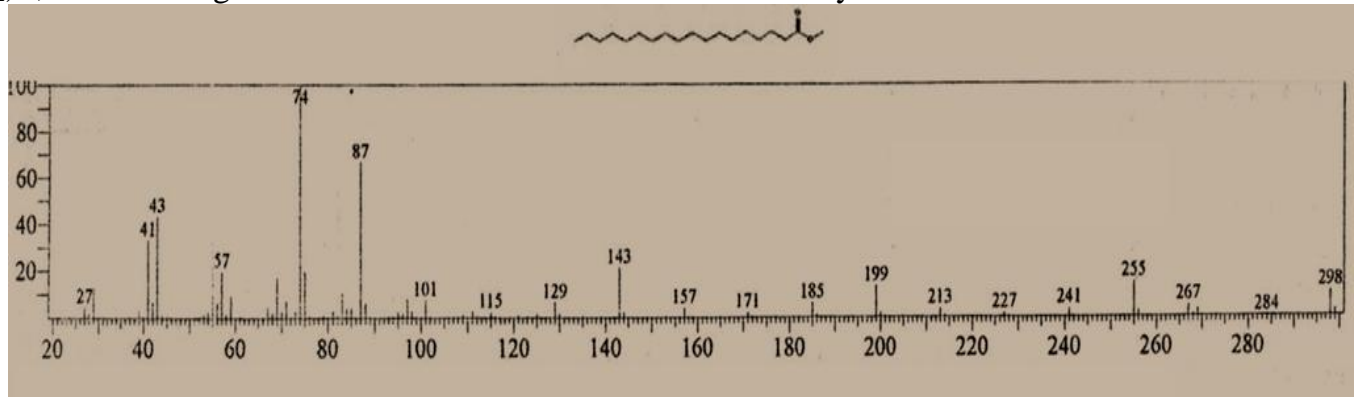

Fig.5:- Mass spectrum of methyl stereate

\section{Antimicrobial assay:-}

Fixed oil from Pennisetum glaucum was screened for antimicrobial activity against six standard human pathogens. Diameters of the growth inhibition zones are displayed in Table 4 .The results were interpreted as follows : 
(<9mm: inative; 9-12mm:partially active; 13-18mm: active; >18mm: very active) .Tables (5) and (6) show the antimicrobial activity of standard drugs.

Table 4 : Antibacterial activity of Pennisetum glaucum oil :M.D.I.Z (mm)

\begin{tabular}{|l|l|l|l|l|l|l|l|}
\hline Drug & Conc. $(\mathrm{mg} / \mathrm{ml})$ & Ec & Ps & Sa & Bs & Ca & An \\
\hline Pennisetum glaucum oil & 100 & 16 & 17 & 14 & 19 & 15 & 14 \\
\hline
\end{tabular}

Table 5 : Antibacterial activity of standard chemotherapeutic agents :M.D.I.Z (mm)

\begin{tabular}{|l|l|l|l|l|l|}
\hline Drug & $\begin{array}{l}\text { Conc. } \\
\mathrm{mg} / \mathrm{ml}\end{array}$ & Bs. & Sa. & Ec. & Ps. \\
\hline Ampicillin & 40 & 15 & 30 & - & - \\
& 20 & 14 & 25 & - & - \\
\hline Gentamycin & 10 & 11 & 15 & - & - \\
\hline & 40 & 25 & 19 & 22 & 21 \\
& 20 & 22 & 18 & 18 & 15 \\
& 10 & 17 & 14 & 15 & 12 \\
\hline
\end{tabular}

Table 6 : Antifungal activity of standard chemotherapeutic agent

\begin{tabular}{|l|l|l|l|}
\hline Drug & $\begin{array}{l}\text { Conc. } \\
\text { mg/ml }\end{array}$ & An. & Ca. \\
\hline Clotrimazole & 30 & 22 & 38 \\
& 15 & 17 & 31 \\
& 7.5 & 16 & 29 \\
\hline
\end{tabular}

* Sa.: Staphylococcus aureus
*.: Escherichia coli
* Pa.: Pseudomonas aeruginosa
* An.: Aspergillus niger
Bs.: Bacillus subtilis

Pennisetum glaucum oil showed activity against all test organisms. It showed excellent activity against Bacillus subtilis and other bacteria except Staphylococcus aureus where a moderate activity was observed . It also showed good activity against the fungal species Candida albicans and moderate against Aspergillus niger

\section{References:-}

1. Amadou,I., Gbadamosi,O.S. and Le,G.W.(2011), Cereal Foods World,56(3),115.

2. Devi,P.B., Vijayabharathi,R., Sathyabams,S.,Malleshi,N.G. and Priyadarisini,V.B.(2012), Journal of Food Science and Technology,52(6),1021.

3. De Wet,J.M.(2006) , Eleusine coracana(L.): Gaertn. Record from Probase; Brink,M. and Betay,G. (eds) ; PROTA (Plant Resources of Tropical Africa), Washington, Netherlands.

4. Grimmer,H.R., parbhoo,V. and McGrath,R.M.(1992),Journal of the Science of Food and Agriculture, 59,251.

5. Girish,C., pakeshkumar,M.,Mahima,D. and Mamta,K.(2015), Current Science,107,7.

6. www.Fao.Org./3/a-av009e

7. Hoseney,R.C., Andrews,D.J. and Clark,H.(1987) ; In : Nutitional Quality of Cereal Grains : Genetic and Agronomic Improvement (eds. Olsen,R.A. and Frey,K.J.), Amer. Soc. Of Agronomy, Madison,PP397-456.

8. Lu,H., yang,X., Ye,M. ,Liu,K.B., Xia,Z. and Ren,X.(2005),Nature,437,13.

9. Montonen,J., Paul,K.,Riva,J., Arpo,A. and Antti,R.(2003),Amer. J. of Clinical Nutrition,77,622.

10. Odusola K B1, Ilesanmi ,F. F., Akinloye O.A., American Journal of Research Communication, $2013,1(6): 262$.

11. Obilana,A.B. and Manyasa,E.(2002), Millets , In: pseudocereala and Less Common Cereals : Grain Properties and utilization Potential, Belton,P.S. and Taylor ,J.R.N. (eds), Springer-Verlag, new York, USA PP. $177-217$.

12. Shweta,M.(2015), IJARIIE,1(3),2395).

13. Taylor,J.R. and Emmambux,M.N.(2008) : " Gluten-Free Foods and Beverages fromMillets " : In ; Arendt,E.K. and Dal-Bello,F.(eds); Gluten-Free Cereal Products and Beveages, San Diego,CA; Elsevier Academic Press,P119-141. 